\title{
An analysis of problem in composing of tsunami contingency plan in Padang City
}

\author{
Zikri Alhadi ${ }^{1,{ }^{*}}$, Karjuni Dt. Maani ${ }^{1}$, Pratiwi Nurhabibi ${ }^{1}$, and Azhari Syarief ${ }^{2}$ \\ ${ }^{1}$ Departement of Public Administration, Universitas Negeri Padang, Indonesia \\ ${ }^{2}$ Departement of Geography, Universitas Negeri Padang, Indonesia
}

\begin{abstract}
Padang city is one of the most vulnerable areas of an earthquake potentially tsunami on the west coast of Sumatra Island. The government should formulate policies to minimize the impact of the disaster. The government and all relevant stakeholders should focus on disaster risk reduction efforts. As part of this effort is making policy in formulating contingency plans to deal with tsunami risk. Padang City Government has developed a contingency plan on tsunami risk since 2013 as a form of public policy. Even though the tsunami has not occurred in Padang City yet, but as a form of evaluation of this policy, it is necessary to analyze the problems in developing the contingency plan of the tsunami for the improvement of its future. Therefore, this article describes the results of the review of problem analysis in the policy of composing tsunami contingency plans in Padang City.
\end{abstract}

\section{Introduction}

According to Joseph Mayunga, a Texas A \& M University disaster researcher, the 2004 Indian Ocean tsunami experience, Katrina and Rita Hurricanes in 2005, and global warming illustrate that people are becoming more vulnerable to natural disasters. It is estimated that in the last ten years, the disaster affected more than 3 billion people, killing more than 750,000 people, and causing losses of more than US \$600 billion. Lots of people died, and property damage show that our society is not sufficiently resistant to natural disasters. Over the past several decades, many authors have emphasized the need to accommodate these issues in research, policy, and disaster risk reduction [1].

Based on LIPI (Indonesian Research Institution) research conducted by geophysicists Hilman, West Coast of Sumatra is the highest vulnerability area of the earthquake and tsunami in Indonesia due to the confluence of two active plate that is a Euro-Asian plate and Indo-Australian plate and because most of its residents are in disaster-prone areas and coastal areas [2]. Padang City as one of the west coast of Sumatera Island suffered a devastating earthquake on September 30,2009 , caused thousands of victims, buildings and public facilities were destroyed during the incident [3].

Disaster risk reduction is local government responsibility and provides protection to the community in accordance with the mandate of Law No. 2 of 2014 on Regional Government and Law Number 24, 2007 on Disaster Management [4]. Due to the high potential threat of a tsunami at Padang City, there should be a handbook of guidelines for reducing risk. The role of government in DRR is interpreted as effective integration of disaster risk reduction considerations into sustainable development policies, plans, and programs at all levels,

with particular emphasis on prevention, mitigation, and disaster vulnerability mitigation. Managing natural disasters is the core of national policy. Therefore, all levels of government should have clear rules and policies for disaster risk reduction and mitigation [5].

Publicly any possible effects of a disaster on risk aversion, time reduction, or mutual trust can substantially affect how people can recover from disasters [6]. In other words, disasters can impact the community not only through the direct harm it inflicts, but also through the willingness of people to try a new business, save, and work cooperatively. Based on experience in disaster management in Indonesia, institutions in do not have sufficient capability, because it is seen from the chaotic governance of disaster starting from the phase of mitigation, responsiveness emergency, and post-disaster. Indonesian local governments in managing disasters have shown that having limited knowledge of disaster management that could potentially lead to more casualties during the disaster. The details can be seen in Table 1 [5].

From table 2 concluded that Padang city had a high risk for a tsunami, both its probability and its impact with the result of the calculation of red column matrix assumptions.

One relevant and vital effort to be undertaken in the tsunami DRR is the future planning process, in an uncertain circumstance, where scenarios and objectives are agreed, technical and managerial measures are established, and potential response and deployment systems are mutually agreed to prevent, or cope with

*Corresponding author: zikrialhadi@fis.unp.ac.id 
the emergency situation faced. This is what according to the National Disaster Relief Agency (BNPB) called contingency plans. contingency planning should include the initial regulatory process so that it can make plans or develop strategies and procedures in response to a potential crisis or emergency that will occur.

Table 1. Local government's problem in implementation disaster management.

\begin{tabular}{|c|c|}
\hline Stage & Problem \\
\hline Mitigation & $\begin{array}{l}\text { - Low community awareness due to } \\
\text { disaster is seen as God's will (pseudo- } \\
\text { fatalistic view); } \\
\text { - Low government commitment (e.g., low } \\
\text { priority and low visibility of government } \\
\text { goals in handling routine tasks and } \\
\text { innovating), ineffective political, } \\
\text { leadership, organizational and financial } \\
\text { pressures. }\end{array}$ \\
\hline Preparedness & $\begin{array}{l}\text { - Early warning systems are inadequate; } \\
\text { - Preparedness education is not evenly } \\
\text { distributed }\end{array}$ \\
\hline Response & $\begin{array}{l}\text { Communication, especially information } \\
\text { flow among agencies; } \\
\text { - Often encountered difficulties in } \\
\text { coordination, both horizontally and } \\
\text { vertically; } \\
\text { - Public information, such as a disaster } \\
\text { early warning system proved to be } \\
\text { inadequate, media reports often } \\
\text { overestimated the extent of the disaster, } \\
\text { increased the content of questions about } \\
\text { the welfare of the local population, and } \\
\text { some victims reported difficulties } \\
\text { encountered in finding family members } \\
\text { during the emergency response; } \\
\text { - Volunteer support, those who are not in an } \\
\text { organized aid agency can receive better } \\
\text { direction and integrate more effectively } \\
\text { with the entire network. }\end{array}$ \\
\hline Recovery & $\begin{array}{l}\text { - Budget constraints; } \\
\text { - Lack of expertise; } \\
\text { - Orders and control of the central } \\
\text { government. }\end{array}$ \\
\hline
\end{tabular}

This includes developing a scenario (crisis anticipated), determine the responsibility of all actors will be involved in identifying the role and resources, the process of data collection and dissemination of information, and setting each actor, so it is ready when needed, and determine the need for the objectives achieved. Contingency planning is an integral part of the overall preparedness program and needs to be developed for each type of hazard, then updated and regularly trained [8]. The definition of extreme disaster is identified and clarified through this literature, while lessons are drawn from this lesson also emphasize the need for contingency planning [9].

Contingency plans are based on scenarios that will likely occur and illustrate the specific incidence of disaster events in terms of time, location, duration, scale, and impact. Arambepola stated, contingency planning also allows the identification of project needs that may arise as a result of emergencies and the resources that will soon be required to meet those needs. With contingency plans, the stakeholders can predict the action will be taken when a disaster comes. Therefore, stakeholders such as government, community, private, and NGOs should work together in developing a comprehensive contingency plan involving all aspects and sects or both physical and nonphysical [10].

Table 2. Description of Disaster Risk Assessment in Padang

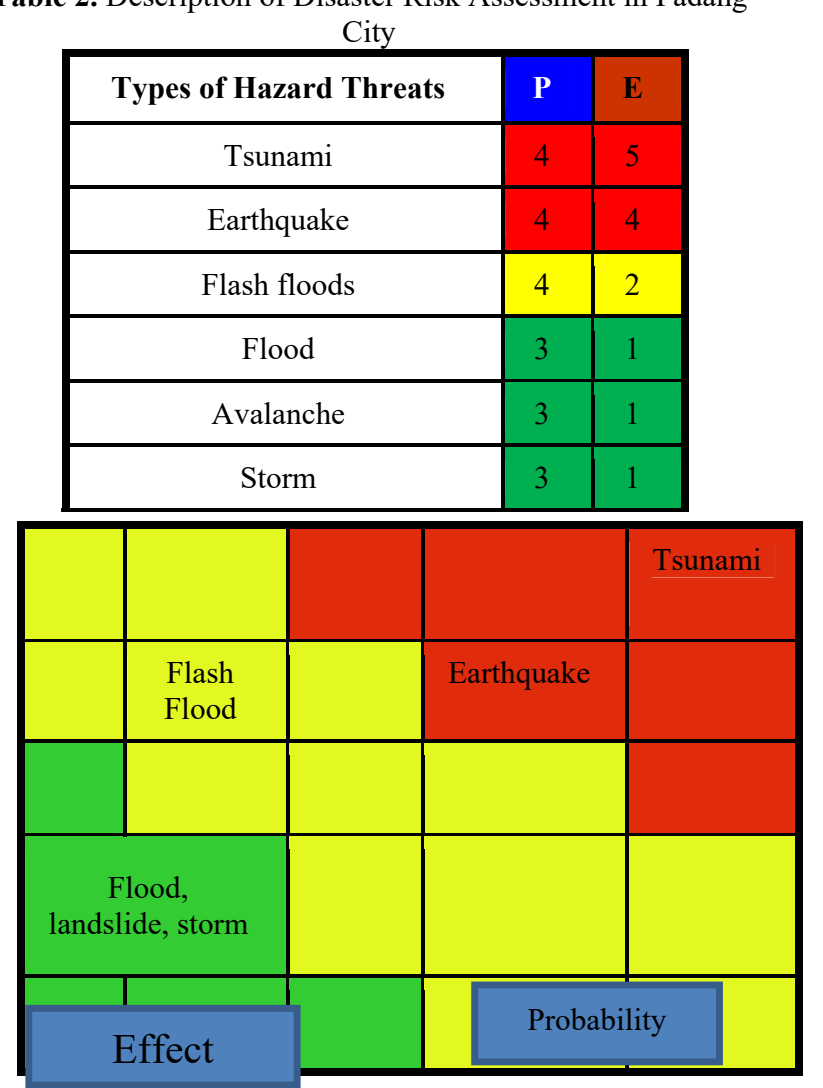

According to IFRC, the purpose of contingency planning is to prepare the institutions to provide the response needed to deal with emergency disasters. The development of a contingency plan involves relevant stakeholders, such as personnel management, budgets, coordination, communication procedures, and logistical availability. Further, there are three essential points in contingency planning: (1) What will happen? (2) What response will we make? and (3) What should we prepare for the emergency? [11].

Developing possible plans involves prior decision making on human management and financial resources, coordination and communication procedures, and realizing technical and logistical responses. Planning on management tools involving all sectors which ensure timely and effective humanitarian assistance for those most in need when disasters occur. So the worst scenario within the tolerance range is managed through contingency planning, which aims to prepare for the worst risks and respond to the worst incidents if a disaster occurs [12-14]. 
Based on the concepts set in the Contingency Plan tsunami in Padang, the policy of this plan is needed as a reference for the tsunami at the time of the emergency response that is rapid and effective, and as the basis for resource mobilization of stakeholders who took part in the formulation of a contingency plan, as set forth in the Indonesian Regulation Number 24,2007 on Disaster Mitigation Article 4 states that disaster management aims to:

a. Providing protection to communities from disaster threats;

b. Harmonizing existing legislation;

c. Ensure the implementation of disaster management in a planned, integrated, coordinated and comprehensive manner;

d. Appreciate the local culture;

e. To encourage public and private participation and partnership;

f. Encourage the spirit of mutual cooperation, solidarity and generosity and;

g. Create peace in the life of society and nation.

There are some fundamental issues in the policy of developing tsunami contingency plans. It found in the observation that some of the trigger factors are:

1. The official has not understood the implementation of the contingency plan, how to activate the contingency plan into an operating plan, or the official who has been given the socialization moved out, then replaced with unsocialized new officials who should not understand the contingency plan;

2. Disaster management training is not sustainable;

3. HR and infrastructure facilities are inadequate. For example, car rescue, evacuation tools, early warning tools, early warning dissemination tools such as a loudspeaker, sirens, ambulances;

4. Lack of human resource competencies in mastering early warning equipment, somehow the amount of power and equipment is not balanced or vice versa.

5. The availability of a minimal disaster management budget at all levels of government.

Therefore, this study will describe the problems in the preparation of tsunami contingency plans in Padang City, seen from the concept of contingency planning itself.

\section{Research methods}

This study used a qualitative approach with descriptive form. Data collection techniques used library research, field research, and in-depth interview. The researcher has interviewed the NGOs and the Government to collect primary data. The interview has been conducted with 6 people from Disaster Risk Reduction Indonesia (DRRI) and 2 people from Komunitas Siaga Tsunami (KOGAMI) as a representative of NGOs and 3 people from Regional Disaster Management Agency (BPBD) as a representative of the government. The data collections were conducted from March until October 2017.

\section{Results and discussion}

In this study, the researcher finds the problem in compiling a contingency plan for the tsunami in Padang City, such as follows :

\subsection{Geographical platform preparation of contingency plan document}

Geographically the Padang city is on the west coast of Sumatra island. Directly facing the Indian Ocean and parallel to the subduction zones of the Indoaustralia and Eurasia plates. The activities of these two plates often result in the activism of tectonism and volcanism on the mainland of the Sumatra island. The highlight of the activity tectonism occurred in 2004 with a massive earthquake of 8.9 on the Richter scale that shook Nanggroe Aceh Darussalam province caused tsunami that destroyed the coast of Aceh and loss of lives of more than 200 thousand inhabitants and material damage.

Administratively Padang city has 11 (eleven) subdistricts, and there are 5 (five) subdistricts with coastlines that will directly impact if a tsunami caused by earthquakes. In the contingency, plan documents have not been defined explicitly on the general description of areas that have characteristically affected by an earthquake and tsunami.

The physical condition of an urban landscape consists of hilly terrain and land directly to the coast. Most of the community activities are in the land area. The description of topography is still in very general information. If it is associated with a tsunami, site altitude information should use very detailed data such as the use of high-resolution IFSAR image data so that a difference of 1-5 meters can be identified. The description of altitude in Padang city can be adjusted to the potential tsunami.

The description of the potential for disaster was not supplemented with preliminary data before deciding that the Padang city had great potential for a tsunami. Whereas in the general picture can be shown the spreading point epicenter of earthquakes that are around the Padang region or the straits of Mentawai and the Indian Ocean. If data about the occurrence of an earthquake can be displayed, it can make a decision on the importance of a tsunami disaster contingency plan.

The province of Western Sumatra has also experienced the earthquake and tsunami disaster in 2012 precisely in the Mentawai islands but didn't hit Padang city. The incident of 2012 is the strength of the earthquake felt in the western part of the island of Sumatra island, but the impact of the tsunami does not reach the coastal Sumatra island where Padang city is located.

\subsection{Risk assessment and potential events}

Risk assessments do not describe locations and areas that are likely to be affected by the tsunami and the extent of damage that will occur and their relation to impacts that will be generated in certain areas. Due to 
the area mapped has not been detailed, the risks cannot be calculated in a more measurable way.

Risk assessment should have reached priority areas for priority handling. There has been no asset analysis and assessment that has the potential to be directly affected by the disaster.

Due to the condition of urban areas dominated by economic and service activities, regional data should have been spatially described with cadaster map, normal maps issued on each unit reaching a scale of 1 : 100 to $1: 1000$.

\subsection{Contingency planning strategy}

The strategy used is scenario analysis by looking at regional capacity. Regional capacity is seen from personnel resources, facilities, and infrastructure resources, then the new strategy is determined. There are 3 different priorities in the determination of the strategy: 1. The safety of the human psyche, 2. Prevention so that the danger is not widespread, do not let the disaster result in secondary disasters even worse, such as floods, evacuate, and refugee camps are not feasible, catastrophic epidemics, plagues, and healing.

Determination plan should be plenary session. The data is listed based on estimation. The drawback is that data is often not available, caused by poor data archiving. The presence of data synchronization between one agency and other agency also trigger the occurrence of differences in the data. Therefore, there should be coordination and mutual agreement from all stakeholders related to the synchronization of data from which agency will be used.

The characteristics in the preparation of the contingency plan itself are to use the worst-case scenario assumption for its occurrence, and for the availability of its resources is minimalize. The following is the findings of the inconsistency between the data in the contingency plan documents and the 2013 central bureau of statistic named BPS data [15$16]$.

Table 3. The difference of data in contingency plan documents with the central bureau of statistic (BPS).

\begin{tabular}{|l|l|c|c|}
\hline No & \multicolumn{1}{|c|}{ Health facility } & $\begin{array}{c}\text { Data of } \\
\text { contingency } \\
\text { plan 2013 }\end{array}$ & $\begin{array}{c}\text { BPS data } \\
\mathbf{2 0 1 3}\end{array}$ \\
\hline 1. & $\begin{array}{l}\text { Community Health } \\
\text { Sub-center }\end{array}$ & 86 unit & 62 unit \\
\hline 2. & Kindergarten & 226 unit & 267 unit \\
\hline 3. & Elementary School & 415 unit & 421 unit \\
\hline 4. & Junior High School & 100 unit & 103 unit \\
\hline 5. & Senior High School & 58 unit & 60 unit \\
\hline 6. & $\begin{array}{l}\text { Vocational High } \\
\text { School }\end{array}$ & 38 unit & 36 unit \\
\hline 7. & University & 20 unit & 60 unit \\
\hline 8. & Place of worship & 617 unit & 1432 unit \\
\hline 9. & Hotel & 67 unit & 53 unit \\
\hline 10. & Beach tourism place & 45 unit & 36 unit \\
\hline
\end{tabular}

\subsection{Scenario Development}

Scenarios create a picture of the incident clearly and in detail about the disaster that is expected to occur the location, timing, and impact. Contingencies plan prepared based on an estimate of the situation (assumptions) to develop an agreed scenario. Due to the rapid dynamics of vulnerability and capacity, the contingency plan needs to be adjusted and updated the scenario [17]. A reasonably detailed scenario is used as a basis for contingency planning and needs to provide space for adaptation because the scenarios are prepared earlier and compiled by experts in contingency plans, may differ from actual disaster [8].

Criticism of presentation of regional resource inventory data is the source and the year are not mentioned. There is only Population data mention that the data is processed based on BPS data in 2011 and Working Group calculations [15].

The researcher assumes that the resource availability data using BPS in 2011 as with the population data then there is a finding of the chronicle between the data contained in the contingency plan with BPS. The researcher then withdraws the assumption that if the data made comes from BPS in 2013 due to the contingency plan prepared in the same year, then the difference in the inventory of resources with those contained in the contingency plan documents will be found. Some of these findings are presented in Table 4 below [15-16]:

Table 4. The difference data between contingency plan documents and BPS.

\begin{tabular}{|l|l|c|c|c|}
\hline No & $\begin{array}{l}\text { Facilities and } \\
\text { infrastructure }\end{array}$ & $\begin{array}{c}\text { Data of } \\
\text { contingency } \\
\text { plan 2013 }\end{array}$ & $\begin{array}{c}\text { BPS } \\
\text { data } \\
\mathbf{2 0 1 1}\end{array}$ & $\begin{array}{c}\text { BPS } \\
\text { data } \\
\mathbf{2 0 1 3}\end{array}$ \\
\hline 1. & $\begin{array}{l}\text { Health Center at } \\
\text { Sub-District } \\
\text { Level }\end{array}$ & 22 unit & 20 unit & $\begin{array}{c}22 \\
\text { unit }\end{array}$ \\
\hline 2. & $\begin{array}{l}\text { Community } \\
\text { Health Sub- } \\
\text { center }\end{array}$ & 86 unit & 62 unit & $\begin{array}{c}62 \\
\text { unit }\end{array}$ \\
\hline 3. & Kindergarten & 226 unit & 401 unit & $\begin{array}{c}267 \\
\text { unit }\end{array}$ \\
\hline 4. & $\begin{array}{l}\text { Elementary } \\
\text { School }\end{array}$ & 415 unit & 402 unit & $\begin{array}{c}421 \\
\text { unit }\end{array}$ \\
\hline 5. & $\begin{array}{l}\text { Junior High } \\
\text { School }\end{array}$ & 100 unit & 100 unit & $\begin{array}{c}103 \\
\text { unit }\end{array}$ \\
\hline 6. & $\begin{array}{l}\text { Senior High } \\
\text { School }\end{array}$ & 58 unit & 74 unit & $\begin{array}{c}60 \\
\text { unit }\end{array}$ \\
\hline 7. & $\begin{array}{l}\text { Vocational High } \\
\text { School }\end{array}$ & 38 unit & 36 unit & $\begin{array}{c}36 \\
\text { unit }\end{array}$ \\
\hline 8. & University & 20 unit & 55 unit & $\begin{array}{c}60 \\
\text { unit }\end{array}$ \\
\hline 9. & Place of worship & 617 unit & 1649 & $\begin{array}{c}1432 \\
\text { unit }\end{array}$ \\
\hline 10. & Hotel & 67 unit & 53 unit & $\begin{array}{c}53 \\
\text { unit }\end{array}$ \\
\hline 11. & $\begin{array}{l}\text { Beach tourism } \\
\text { place }\end{array}$ & 45 unit & 24 unit & $\begin{array}{c}36 \\
\text { unit }\end{array}$ \\
\hline & \multicolumn{2}{|c|}{} & & \\
\hline
\end{tabular}

Associated with the phenomenon of gaps in data collection feel there are two functions of the data used in 
the contingency plan which can be seen in the picture below [18]:

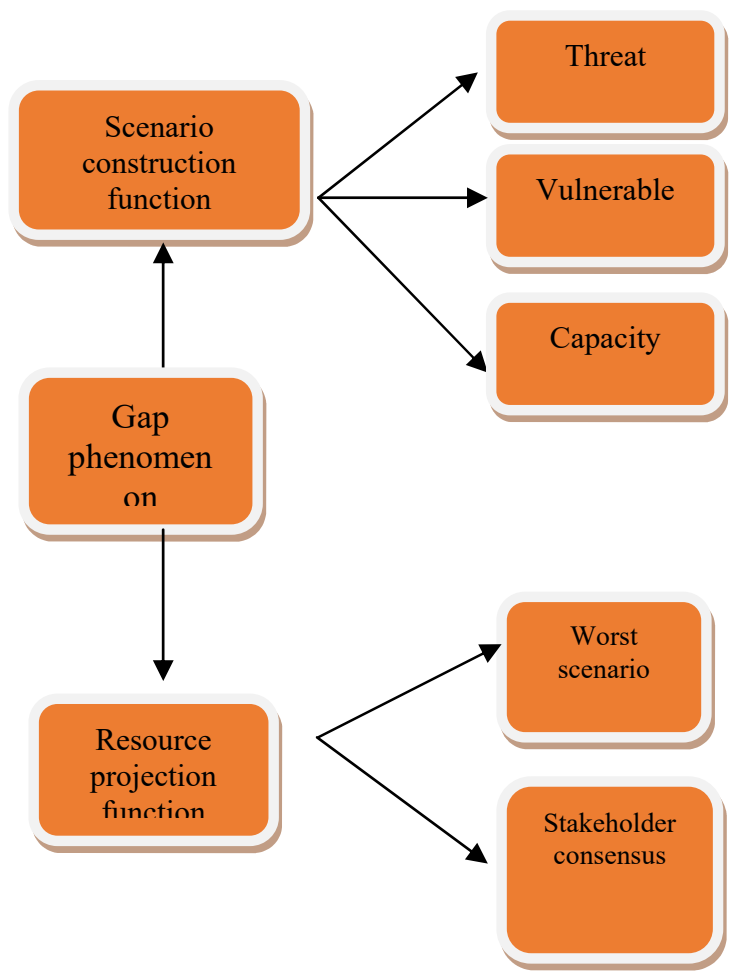

Fig.1. Data functions in the preparation of the Disaster Contingency Plan

The explanation of the picture above is as follows:

\section{a. Scenario construction function}

In this function, in determining the overview of the situation or scenario of events using the Disaster Risk Assessment (KRB). This KRB issued 3 parameters, as described in the Head Regulation of BNPB No. 2, 2012 that the disaster risk assessment component consists of threats, vulnerabilities, and capacities. This component is used to obtain the level of disaster risk an area to calculate the potential of exposed souls, property losses, and environmental damage.

\section{b. Resource projection function.}

In making a projection of resources, it is complicated to determine the exact amount of availability. The data is very dynamic data changes. The availability of resources will not always be the same from time to time. Data created before a disaster and when a disaster will be different. So given the constantly changing data, the way around this is through the worst-case scenario determination mechanism. The determination of such data is based on a participatory, participative-based consensus. Communication Forum Regional Head who has the authority to do a deal to make Emergency Response Plan and contingency plan data.

\subsection{Operational thinking emergency response flow}

The flow of thought in emergency management should have targets, strategies, and tactics. In disaster response, the first priorities are to save the life. Secondly, the stability of the emergency and third save assets. In fact, in emergency response, people are more concerned with saving assets, which talk about the accuracy of the data occurs.

If in the preparation of worst operating scenarios using very detailed data then the gap is potentially too large because the data used is live data. Live data cannot be made into raw data. The more detailed the data is calculated, the more deviations, the less accommodated, cannot save lives properly, and cannot handle the emergency response properly.

\subsection{Data collection strategy in contingency plan} The strategy used is scenario analysis by looking at regional capacity, the new strategy is determined. Regional capacity is seen from :

1. personnel resources of the institution that involved in disaster emergency operation. Such as regional disaster management agency (BPBD); Indonesian National Army (TNI); Indonesian National Police (POLRI); civil service police unit (Satpol PP); Social service Office (Dinsos); transportation office (Dishub), Communication and Informatics Office (Diskominfo); health Office (Dinkes); Department of Public Work (Dinas PU); search and rescue (SAR); Indonesian red cross society (PMI); National unity, politics, and community protection agency (Kesbangpolinmas); fire office (Dinas Damkar); state electricity company (PLN); and local water supply utility (PDAM)

2. facilities and infrastructure resources owned by the government. There are a hospital, transportation, ambulance, etc.

There are 3 different priorities in the determination of the strategy: 1 . The safety of the human psyche, 2 . Prevention of the danger is not widespread, do not let the disaster result in secondary disasters even worse, such as floods, evacuate, and refugee camps are not feasible, epidemic disasters, epidemics, and 3 . Recovery.

The data is listed based on estimation. The drawback is that data is often unavailable, caused by poor data archiving. The unsynchronized data between one agency and other agency also trigger the occurrence of data differences. Therefore, there must be coordinate and agreement of all stakeholders related to the synchronization of data from institutions which will be used. The characteristic in the preparation of the contingency plan itself is to use bad scenario assumptions for its occurrence, and for the availability of its resources made minimally.

\subsubsection{Fulfillment Strategy}

There is a gap between the community needs in the emergency response phase with the availability of local resources. The explanation in the contingency plan is 
only an assumption with the analysis used according to the standard. Standards used include the standard sphere issued by the UN or standards issued directly by the region in accordance with the collective agreement. For example, standardized use agreements are tailored to the medical or health field. The research informants explained that there is a gap in the assumption between the community needs and the resources available, such as the Padang city only has 5 ambulances which mean cannot be fulfilled the needs when the disasters happen.

Therefore, in contingency plan enacted fulfillment strategy. So that how much ambulances the agencies should add. Such fulfillment strategies are discussed within the contingency plan. The mode of the fulfillment of resources is left to a responsible agency. The fulfillment of these needs is measured only by government resources or how much the government can manage. The parties outside the government are not involved because it is difficult. The difficulties are caused, among others:

1. Complicated command system. When disaster strikes, it is only a rapid command system by the government can be applied, whereas if from a nongovernmental organization take a long time and cannot instantly be done.

2. The difference of the actual scene location with scenario location. At the time of the contingency plan, the location is in a particular area, but when the disaster occurs its location is in another region.

The contingency plan in its document contains the worst disaster scenario in an area, but the resource scenario is made the minimum, which may be fulfilled by the area. As the result of an interview with an informant as follows Gap analysis in the fulfillment of needs means is a gap between the availability and needs, the approach through each agency. Not always the fulfillment of the strategy can be implemented because it is related to the government budget.

\subsubsection{Form stakeholder commitment}

In general, the commitment of the Padang City Government in the tsunami contingency plan policy is good (100\%) and medium (50\%). Determination of the categories of good and medium is seen from different aspects. Viewed from the commitment aspect to attendance and participation then this is said to be good because some responsible agencies present in the meeting. Meanwhile, the government's commitment is said to be only $50 \%$ which is good because of the obstacles in terms of administration, then the officers who are dispatched do not have the authority as a policy maker so challenging to spawn into a decision.

In reality, there is no a single guideline in the contingency plan, where references have not been made. In the law no. 24 of 2007 there is no obligation of local governments to draw up a contingency plan on disaster risk. However, the suggestion to formulate a new contingency plan is in Presidential Decree No 21 of 2008 on disaster management that is complementary to disaster emergency response.
The tsunami disaster event in Aceh Region occurred in 2004 caused many sectors to move massively to cope with the disaster in Indonesia. Public institutions and international NGOs offer and try to apply the concept of disaster management that they set up to be applied in Indonesia. A concept is the preparation of disaster risk contingency plan documents. The disaster management law states that the obligation that must be drafted by the regions is the disaster emergency response plan (RPKB). The RPKB is then defined as a standard operating procedure for all disaster emergency response comprehensively. On the other hand, the contingency plan is only for one type of disaster in Indonesia, known contingency plan than RPKB. In comparison in abroad unfamiliar with the contingency plan, there is only an operating plan. Such the concept in Japan, the Disaster Management Plan compiled by it already contains the concept of a contingency plan.

\section{Conclusions}

The description of the potential for disaster was not supplemented with preliminary data before deciding that the Padang city had great potential for a tsunami. Whereas in the general picture can be shown the spreading point epicenter of earthquakes that are around the Padang city or the straits of Mentawai and the Indian Ocean. If data about the occurrence of an earthquake can be displayed, it can make a decision on the importance of a tsunami disaster contingency plan. In addition, the assessment of risks should have reached priority areas for priority handling or more disaster prepared personnel. There has been no asset analysis and assessment that has the potential to be directly affected by the disaster.

The tsunami contingency plan should contain the worst case of disaster occurrence in an area, but the resource scenario is made the minimum, which can be fulfilled by the area. Gap analysis in the fulfillment of needs means that there is a gap between availability and demand, the approach is through the respective agencies. all the strategies cannot be fulfilled because it is related to the government budget. In general, the commitment of Padang City Government in the policy of tsunami contingency plan is said to be good (100\%) and medium $(50 \%)$. Determination of the categories of good and medium is seen from different aspects. Viewed from the commitment aspect to attendance and participation then it is said to be good because some responsible agencies present in the meeting. Meanwhile, the strategic plan is plenary. The data to be listed based on estimation. The drawback is that data is often unavailable, caused by poor data archiving. The unsynchronized data between agency also trigger the occurrence of differences in the data, ie, with no sources and years of the data covering the components of facilities and infrastructure, government, economy, and environment. Only Population data only mentions that the data is processed based on BPS data in 2011 and the team calculations. 
In the preparation of the worst operating scenarios using very detailed data then the gap is potentially too large because the data used is live data. Live data cannot be made into raw data. The more detailed the data is calculated, the more deviations, the less accommodated, cannot save lives properly, and cannot handle the emergency response properly. And the data to be listed based on estimation. The drawback is that data is often unavailable, caused by poor data archiving. The existence of data synchronization between agencies also become trigger the happening of difference in data

\section{References}

1. J. S. Mayunga. Understanding and applying the concept of community disaster resilience: a capital-based approach. Summer Academy for Social Vulnerability and Resilience Building, 1, 16. (2007).

2. D.Hilman. Evaluation of Active Fault Hazards, Tsunami and Earthquake Shock. (LARIBA LIPI, Jakarta, 2008).

3. Z. Alhadi. The readiness of Paths and Locations of Public Evacuation to Face Risks of Earthquake and Tsunami Disasters in Padang City (Disaster Management Study). Humanus, 13(1), 35-44 (2014).

4. J. S. Mayunga. Understanding and applying the concept of community disaster resilience: a capital-based approach. Summer Academy for Social Vulnerability and Resilience Building, 1, 16. (2007).

5. B.Kusumasari,.Disaster Management and Local Government Capabilities. (Gava Media, Yogyakarta, 2014).

6. A.Cassar, A. Healy \& C. V. Kessler.Trust, risk, and time preferences after a natural disaster: experimental evidence from Thailand. World Development, 94, 90-105 (2017).

7. BPBD Kota Padang. Tsunami Contingency Plans Document of Padang. (Padang City Government - UN OCHA, 2013).

8. H. D. Vidiarina. Contingency Planning Overview of some Planning Guidelines and Contingency Plans. (GTZ-International services, Jakarta, 2010).

9. H.AlShamsi\& C. Pathirage.The Role of Effective Contingency Planning in Managing Extreme Disasters in UAE. International Postgraduate Research Conference. (2015).

10. N. M. S. I Arambepola, M. A Rahman\& K. Tawhid. Planning Needs Assessment for Responding to Large Disaster Events in Cities: Case Study from Dhaka, Bangladesh. Procedia

11. IFRC.Contingency Planning Guide. (Geneva, Switzerland, 2012)

12. J.C Manceau, D.G.Hatzignatiou, L.D.Lary, N.B. Jensen, K.Flornes, T.L.Guenan, A. Reveillere, Methodologies and Technologies for Mitigation of Undesired CO2 Migration in the Subsurface. (IEAGHG, UK, 2013).
13. K.Farhat\& S. M. Benson. Translating Risk Assessment to Contingency Planning for $\mathrm{CO} 2$ Geologic Storage: A Methodological Framework. International Journal of Greenhouse Gas Control. 52, 410-431 (2016).

14. S.Vajjhala, J. Gode, \& A. Torvanger. An international regulatory framework for risk governance of carbon capture and storage. Policy note/CICERO-Senter for klimaforskning http://urn. nb.no/URN: NBN: no-3647 (2007).

15. BPS. Padang in Figures. (2011).

16. Padang in Figures.(2013).

17. BNPB. Contingency Planning Guide for Disaster Management :vol 2. (Jakarta, 2011).

18. Head Regulation of BNPB No. 2 in 2012 about The Disaster Risk Assessment 